\title{
APRENDER E ENSINAR A ESCRITA: CONTRIBUIÇÕES DOS NOVOS ESTUDOS DO LETRAMENTO NA FORMAÇÃO INICIAL DE PROFESSORES DE LÍNGUA
}

\section{LEARNING AND TEACHING THE WRITING: CONTRIBUTIONS OF THE NEW LITERACY STUDIES IN THE INITIAL FORMATION OF LANGUAGE TEACHERS}

\section{Giselle Cristina Smaniotto*}

Resumo: Este artigo tem como objetivo promover uma reflexão teórica a partir dos Novos Estudos do Letramento, relacionando as discussões sobre as práticas sociais da escrita no ambiente acadêmico e suas implicações para a formação dos professores de língua materna. Para tanto, resgata estudos de Street (2006 [1994]) e de autores brasileiros, entre eles, Rojo (2009), Kleiman (2001, 2008), Oliveira (2006), Guedes-Pinto (2012), que discutem conceitos como letramento ideológico, letramento pedagógico, formação de professores de línguas e identidades docentes. Tais estudos ressaltam que as práticas formadoras devem estar fundamentadas em práticas sociais, situadas sócio-histórica e ideologicamente, que oportunizem a participação dos sujeitos em práticas de letramentos acadêmicos e de letramentos pedagógicos de modo a promover a constituição das identidades de aluno do ensino superior e de professor para ensinar a escrita na Educação Básica.

Palavras-Chave: Letramentos. Formação docente. Escrita.

ABSTRACT: This article aims to promote a theoretical reflection based on the New Literacy Studies, relating the discussions about the social practices of writing in the academic environment and its implications for the development of mother language teachers. In order to do so, it rescues studies of Street (2006 [1994]) and Brazilian authors, among them, Rojo (2009), Kleiman (2001, 2008), Oliveira (2006), Guedes-Pinto, which discuss concepts such as ideological literacy, pedagogical literacy, language teachers training and teacher identities. Such studies emphasize that the training processes must be based on social practices, situated socio-historically and ideologically, that allow the participation of the subjects in academic and pedagogical literacy practices

\footnotetext{
"Docente do Departamento de Pedagogia na área de Alfabetização e Língua Portuguesa. Doutoranda no Programa de Pós Graduação em Linguística - Universidade Federal de Santa Catarina. Email: gisellesmaniotto@yahoo.com.br.
} 
in order to promote the development of the students' identities of higher education and teachers to teach writing in Basic Education.

KEY Words: Literacy. Teacher training. Writing.

\section{Considerações INICIAIS}

É comum ouvirmos queixas, no ambiente universitário, sobre as dificuldades em leitura e escrita dos acadêmicos, seja da parte dos professores formadores ou dos próprios estudantes que, muitas vezes, sentem-se despreparados e aquém das expectativas desse contexto. Essa preocupação se intensifica quando esse acadêmico é um futuro professor de língua materna (acadêmico/a dos cursos de Letras e Pedagogia), pois se ele apresenta "dificuldades" com a escrita como poderá ensiná-la na Educação Básica?

Esse texto se propõe a refletir sobre a relação do futuro professor com a escrita na universidade e sobre sua formação para ensiná-la a partir de conceitos dos Novos Estudos do Letramento (NEL) que nos auxiliam a rejeitar o "discurso da defasagem" $\mathrm{e}$ compreender que este sujeito está em pleno processo de letramento em novas práticas sociais. Além disso, queremos refletir sobre como o futuro professor, ao participar das práticas de letramento em sua formação inicial, constitui sua identidade profissional e assume-se como aquele que (vai) ensina(r) a escrita na Educação Básica.

Desse modo, perguntamos: Como os Novos Estudos do Letramento, considerando a sua vertente dos Letramentos Críticos ${ }^{1}$,

1"O desdobramento pedagógico, por assim dizer, da adoção dos NEL na educação é amplamente divulgado como podem contribuir para pensarmos o ensino e a aprendizagem da escrita na formação inicial de professores de língua materna - no âmbito dos cursos de Pedagogia e Letras - e seu posterior ensino na Educação Básica? Para tanto, esse trabalho tem como objetivo promover uma reflexão teórica a partir dos Novos Estudos do Letramento, relacionando as discussões sobre as práticas sociais da escrita no ambiente acadêmico e suas implicações para a formação dos professores de língua materna.

Para isso nos ancoramos na perspectiva da Linguística Aplicada e buscamos apresentar estudos e pesquisas que se fundamentam nos Novos Estudos do Letramento. Partimos das proposições de Street (2006[1994]) e relatamos reflexões teóricas e resultados de pesquisas de autoras brasileiras como Rojo (2009), Kleiman (2001, 2008), Fiad (2011), Guedes-Pinto (2012) entre outras, que discutem a escrita na universidade e os letramentos acadêmicos, como também pesquisas que consideram a formação e constituição docente do acadêmico, especialmente, dos cursos que preparam para o ensino da língua.

Diante do exposto, primeiramente, fazemos uma breve discussão sobre o conceito de letramento, evidenciando as diferenças de abordagem dos seus modelos autônomo e ideológico. Também abordamos a relevância

Letramento Crítico". (BALADELI, 2014, p. 230) 
das variadas práticas de letramento em contextos múltiplos, e sua relação com a formação de identidades, em contraponto à (falsa) ideia de um letramento único e dominante. Na seção seguinte, apresentamos algumas considerações reflexivas a respeito das contribuições dos estudos do(s) letramento(s) para a formação dos professores.

\section{LETRAMENTOS NA UNIVERSIDADE}

O termo e o conceito de letramento chegam ao Brasil na década de $80^{2}$. Desde sua primeira aparição no livro de Mary Kato $(1986)^{3}$ este conceito tem sido discutido e tem passado por revisões que ampliam sua abrangência e importância. Neste trabalho assumimos uma concepção de letramento tal qual exposta por Rojo (2009, p. 98) ao diferenciá-lo de alfabetismo:

o termo letramento busca recobrir os usos e práticas sociais de linguagem que envolvem a escrita de uma ou de outra maneira, sejam eles valorizados ou não valorizados, locais ou globais, recobrindo contextos sociais diversos (família, igreja, trabalho, mídias, escola etc.), numa perspectiva sociológica, antropológica e sociocultural.

Kleiman (2001 [1995]) corrobora com essa concepção. Para a autora o letramento é “[...] um conjunto de práticas sociais que

\footnotetext{
${ }^{2}$ Soares (2004) apresenta um histórico do surgimento do termo e do conceito no Brasil. SOARES, M. Letramento e alfabetização: as muitas facetas. Revista Brasileira de Educação, n. 25, p. 5-17, Jan./Abr. 2004. Disponível em: http:// www.scielo.br/pdf/rbedu/n25/n25a01.pdf.

${ }^{3}$ KATO, M. No mundo da escrita: uma perspectiva psicolinguística. São Paulo: Ática, 1986.
}

usam a escrita, como sistema simbólico e como tecnologia, em contextos específicos, para objetivos específicos" (p.18-19, grifos nossos). As expressões em negrito nas citações acima procuram destacar que a ênfase ao pensarmos em letramentos recai sobre as práticas sociais nas quais a escrita é a tecnologia mediadora. Dessa forma, ressaltamos a importância de utilizarmos a escrita para nos inserirmos e participarmos de diferentes práticas sociais que nos constituem como sujeitos sociais com identidades próprias.

Partimos dos estudos de Brian Street que, em 1984, inaugura os Novos Estudos do Letramento (NEL) e descortina uma nova percepção sobre o letramento, passando a falar em letramentos, no plural, pois são múltiplos e situados social, histórica, cultural, política e ideologicamente. $O$ autor propõe uma divisão entre um enfoque autônomo e um enfoque ideológico do(s) letramento(s). No modelo autônomo de letramento as práticas com a escrita são individuais e autônomas, são vistas pelo viés técnico e são entendidas como "neutras", independente do contexto social. Espera-se que o letramento por si só promova a transformação da sociedade. Rojo (2009, p. 99) acrescenta que o modelo autônomo em sua versão fraca é "(neo) liberal e estaria ligada a mecanismos de adaptação da população às necessidades e exigências sociais do uso da leitura e da escrita, para funcionar em sociedade".

No modelo ideológico, defendido pelo autor e ao qual nos vinculamos, considera-se a relação intrínseca das práticas de leitura e escrita às estruturas culturais e de poder 
de diferentes contextos. Street (2006 [1994], p. 466), mencionando trabalhos anteriores, ao defender a modalidade ideológica do letramento,

reconhece uma multiplicidade de letramentos; que o significado e os usos das práticas de letramento estão relacionados com contextos culturais específicos; e que essas práticas estão sempre associadas com relações de poder e ideologia: não são simplesmente tecnologias neutras. (STREET, 1985, 1993).

$\mathrm{Na}$ versão forte do letramento ideológico, Rojo (2009) afirma que, contrariamente à adaptação do cidadão às demandas da sociedade (como no modelo autônomo), se promove sua emancipação, de modo crítico, revolucionário e empoderado. É importante lembrar que para Street "o modelo ideológico não ignora a importância de aspectos técnicos dos letramentos, [...] mas sustenta que esses aspectos decorrem de interações em práticas sociais específicas, com relações de poder e ideologias". (COLAÇO, 2015, p. 29)

Street (2006 [1994]) exemplifica com inúmeras pesquisas que as práticas de letramentos independem do contexto escolar e estão presentes em todas as culturas e contextos. Dessa forma, há múltiplos letramentos e o letramento dominante é apenas uma das variedades de letramento que se tornou padrão por uma questão de poder, por isso é apresentado como único (p.472). Entretanto, as diferentes práticas de letramentos são apropriadas e desenvolvidas pelas pessoas, de acordo com os contextos culturais, e são permeadas por ideologia e poder.
O pesquisador destaca a relação entre letramento(s) e identidade(s). Para o autor as práticas de letramento são constitutivas da identidade e da pessoalidade: "quaisquer que sejam as formas de leitura e escrita que aprendemos e usamos, elas são associadas a determinadas identidades e expectativas sociais acerca de modelos de comportamento e papéis a desempenhar" (p.466). Logo, há a necessidade de pensarmos na especificidade da escrita no contexto acadêmico e na sua relação com a formação de identidades, pois é nas práticas letradas da esfera acadêmica que o estudante das licenciaturas passa a desenvolver suas identidades, de estudante do ensino superior e de futuro professor.

Os Novos Estudos do Letramento podem nos ajudar a (re)pensar as relações do universitário com a escrita na esfera acadêmica. Ensinar a escrita no ensino superior não se limita a identificar as características linguísticas e discursivas dos gêneros trabalhados, pois a interação com a escrita nesse contexto exige o vislumbrar das práticas sociais que os originam e as relações que ali se estabelecem. Juchum (2014) cita alguns dos principais estudiosos da área dos NEL (STREET, 1994, 2003; BARTON, 1994; GEE, 1996) que "propõem que as práticas de letramento, como práticas sociais que são, têm caráter situado, ou seja, têm significados específicos em diferentes instituições e grupos sociais" (p. 112). Dessa forma, a especificidade da escrita universitária necessita ser considerada e estudada à luz dos estudos dos letramentos. Várias pesquisas têm demonstrado a relevância dessa abordagem. 
Juchum (2014) argumenta a partir de suas pesquisas que os alunos reconhecem suas dificuldades e até apreensões em relação às práticas de escrita na universidade e deixam explícito que escreviam outros gêneros e que na academia terão de aprender a escrever textos que desconhecem e com linguagem específica. Entretanto, isso não significa que sejam iletrados, mas sim que necessitam participar de práticas de letramento até então desconhecidas para apropriarem-se de novas formas de interação. Na mesma direção, Fiad (2011) ao apresentar resultados de análise da escrita de universitários, abordando o que eles dizem sobre suas escritas, mais especificamente, como suas escritas são vistas em confronto com o que é esperado no contexto acadêmico, afirma que "Se, antes, era possível ver o desempenho na escrita como habilidades individuais de ler e escrever, adquiridas principalmente na escola, hoje é necessário situar qualquer prática envolvendo a leitura e a escrita em um contexto sócio-histórico-cultural específico" (p. 360).

Esses estudos, entre tantos outros, mostram que os alunos universitários, muitas vezes, assumem-se como receptores dos textos escritos pelos produtores mais experientes e não se sentem capazes de produzir os gêneros que circulam na academia, além de muitos formadores acreditarem que não é necessário explicitar/ensinar as especificidades dos gêneros trabalhados. É clara e explícita a relação entre escrita e poder no contexto acadêmico. Dessa forma, alerta Botelho (2016), que cabe ao professor (considerado como aquele que "tem o poder") promover a aproximação dos estudantes às práticas sociais de produção desses gêneros, proporcionando a sua análise, compreensão e produção, já que eles são insiders nessa esfera e é nela que aprenderão a participar das práticas que ali se constituem.

Ao considerarmos a atuação desse acadêmico como futuro professor de línguas na Educação Básica, os estudos críticos sobre os letramentos também se revelam importantes, pois

a proposição de práticas pedagógicas críticas que mobilizem não só conhecimentos escolares, mas também questões socioculturalmente relevantes à formação crítica do aluno, tornam-se indispensáveis para a compreensão das relações de poder e da influência cultural dos grupos dominantes. (BALADELI, 2014, p.228)

Em estudo que também analisa a escrita de universitários, mas com o objetivo de investigar como eles "projetam seu papel como graduandos e futuros professores que trabalham(rão) em contexto caracterizado por (novas) práticas de leitura e escrita." (p. 9), Frota (2013) analisa 53 produções textuais de acadêmicos de um curso de Licenciatura em Letras de uma universidade pública. $\mathrm{O}$ pesquisador constatou, baseado na argumentação dos textos, entre outros resultados, que o universitário vive um conflito "entre o que a instituição acadêmica oferece e aquilo de que ele necessitaria em sala de aula" (p. 9), ou seja, prevalece o discurso de que a instituição não prepara adequadamente o profissional para sua atuação na escola. Outro resultado que nos chama a atenção, e que se relaciona com o que estamos discutindo, é 
que o universitário não estabelece um diálogo com o discurso acadêmico-científico, distanciando-se da instituição, mesmo durante sua formação.

Portanto, cabe aos formadores promover, além das práticas sociais próprias ao ambiente acadêmico, a discussão de conceitos dos NEL que contribuirão para a formação do futuro docente e sua atuação, na busca por processos de ensino e aprendizagem mais críticos e relevantes.

\section{LETRAMENTOS E A FORMAÇÃO DO DOCENTE DE LÍNGUA MATERNA}

Estudos de diferentes áreas, entre eles os NEL, são fundamentais para pensarmos a formação de professores de línguas, pois ela não pode ser estritamente relacionada ao domínio dos conhecimentos linguísticos, mas, como afirma Cavalcanti (2013, p. 212), envolve "enfatizar a formação de um professor posicionado, responsável, ético, leitor crítico, com sensibilidade à diversidade e pluralidade cultural, social e linguística etc." Uma formação nessa perspectiva implica a interface com outros campos de saber e aí vislumbra-se o papel da Linguística Aplicada a partir da problematização crítica dos currículos dos cursos de formação docente, de maneira que a educação linguística amplie-se na direção de que todo o uso linguístico seja compreendido em suas práticas sociais, permeadas de implicações políticas, ideológicas e culturais. Para Cavalcanti (2013, p. 226):

A educação linguística do professor de língua não pode ser somente linguística, ela precisa ser sofisticadamente inter-e transdisciplinar, socialmente engajada, antropologicamente antenada, plural em seu foco, para incluir os estudos de letramento, os estudos sobre multilinguismo com as questões de intercompreensão e de práticas translíngues, os estudos sobre transculturalismo. (grifos nossos)

Oliveira (2006) discute a relação teoria-prática e identidades na formação de professores de língua. A autora reconhece a importância dos estudos que valorizam os saberes da prática (epistemologia da prática), entretanto, questiona sua supervalorização em detrimento ao reconhecimento da imprescindibilidade dos conhecimentos científicos, o que pode resultar em um praticismo. Dessa forma, há a necessidade de se redimensionar a teoria, reconhecendo-se a sua importância para a análise da prática e vice-versa, "sem criar um abismo entre o mundo da ciência e o mundo da vida" (p. 105). Para a pesquisadora trata-se, enfim, de estabelecer um diálogo constante entre teoria e prática e rever os currículos dos cursos de Letras, pois, como a maioria se apresenta, acaba por formar uma identidade do professor como "transmissor de conhecimentos", identidade que é rejeitada, pois se refere a práticas ultrapassadas. (p.107)

Somente com uma formação ampliada e que considere os estudos de letramento, poderemos abandonar o "discurso da crise" em relação à leitura e à escrita na universidade (cf. JUCHUM, 2014; FIAD, 2011, entre outros) e promover situações de ensino e aprendizagem baseadas em práticas sociais autênticas e relevantes para a (trans) formação de identidades de alunos a professores. Para tanto, o foco na formação 
docente deve estar na prática social e nos letramentos acadêmicos que promovam não só o aprender a usar a escrita, mas também o aprender a ensiná-la. Dessa forma, os gêneros discursivos que serão mobilizados atenderão as demandas das práticas nas quais os sujeitos estiverem envolvidos. Essa forma de estruturar o ensino é defendido por Kleiman (2008, p. 508):

A estruturação do ensino em torno da prática social é uma estratégia de didatização que, na nossa experiência, tem se mostrado eficiente e relevante na formação de professores, fornecendo um modelo que pode, depois, ser recontextualizado pelo professor na sua esfera de atividade, do ensino escolar.

Kleiman (2008) defende o ensino baseado nas práticas sociais e também destaca a importância dos saberes pedagógicos, ou seja, além de saber usar a escrita e de conhecer a especificidade da matéria pela qual será responsável na escola, o professor precisa desenvolver saberes para ensiná-la, e só as teorias linguísticas são insuficientes, por isso a autora defende um letramento para o/no trabalho. Ela enfatiza a necessária inserção dos "futuros professores de língua escrita, na prática social acadêmica, quando estão na universidade, e da exploração e resgate das práticas de letramento nas atividades de seu cotidiano [...]" (KLEIMAN, 2008, p. 510) A pesquisadora também ressalta que o trânsito por práticas de letramentos acadêmicos, "pela via da ação em diversas práticas sociais" (p. 510), são mais importantes na formação do professor de língua materna do que o raso conhecimento de teorias.
Assim, acreditamos ser possível dizer que é o professor familiarizado com as práticas de letramento acadêmicas (entre outras) quem determina quais são os limites e as possibilidades dos saberes teóricos que subsidiam sua disciplina de ensino. Sem os demais saberes, perceberá constantemente os limites dos saberes especializados; munido de outros saberes, multiplicará as possibilidades acenadas pelo saber teórico, em função da segurança decorrente de seu conhecimento sobre o funcionamento da linguagem. Portanto, em última instância, somos nós, os formadores dos professores, que demarcamos os limites, mas, sobretudo, as interfaces potencializadoras dos saberes teóricos e a prática social no ensino da língua escrita." (KLEIMAN, 2008, p. 512)

Colaço (2015) também reconhece a importância dos saberes para a prática e os nomeia de letramento pedagógico: "Todo esse conjunto de textos [pedagógicos], saberes, atitudes, valores que um professor precisa ter constituem os letramentos pedagógicos" (p. 38). Ela ressalta que as práticas de letramento pedagógico ao inserirem os sujeitos nas salas de aula da Educação Básica, promovendo a interação desses com as ideologias e relações de poder ali presentes, propiciam a formação das identidades de professor. (p. 50) A pesquisadora acrescenta ainda que nas leituras e escritas dos sujeitos, tanto em seu letramento acadêmico como no letramento pedagógico, ficam as marcas de suas (trans) formações na constituição de suas identidades como docentes. Essa afirmação de Colaço confirma a indissociabilidade entre 
letramentos e identidade, tal como defendido por Street (2006 [1994]).

Na esteira da discussão sobre o papel das práticas de escrita no contexto de formação inicial dos professores de língua, GuedesPinto (2012), em consonância com as autoras supracitadas reforça que "A discussão sobre a produção escrita de estudantes universitários requer que ela seja atrelada ao seu contexto, às suas demandas específicas." (p. 140) A autora também ressalta a importância da inserção no ambiente de trabalho para o processo de formação docente. A partir de pesquisa realizada com seus próprios alunos, a autora relata como as produções de relatórios e textos reflexivos dos estudantes após a experiência de inserção no cotidiano escolar contribuiu para a formação docente desses estudantes, proporcionando a construção de uma identidade não mais de aluno, mas de professor. Conforme a autora: "Ao sistematizarem suas dúvidas, dificuldades e conflitos protagonizados com os sujeitos da escola, trazem à tona o desafio de se posicionarem e de refletirem sobre a profissão docente." (p. 147)

Portanto, o trabalho com a escrita, tanto na formação do futuro docente quanto em sua atuação na Educação Básica, precisa estar pautada numa concepção de língua como prática social e por isso os estudos dos letramentos são fundamentais. Finalizamos essa discussão reafirmando a importância e necessidade de como formadores levarmos a efeito práticas de letramentos acadêmicos e de letramentos pedagógicos para a formação do futuro professor de línguas. Também reconhecemos, assim como os autores aqui mencionados, que o estudante precisa vivenciar tais práticas, refletir sobre elas para constituir sua identidade docente a fim de que em suas futuras ações no ensino da língua escrita na Educação Básica possa assumir posturas críticas, que tenham como foco as práticas sociais e o trabalho a partir dos múltiplos letramentos.

\section{Considerações (QUASE) FINAIS}

Os Estudos dos Letramentos a partir de conceitos como o modelo ideológico do(s) letramento(s), as práticas (plurais) de letramento em oposição a um letramento único e dominante, a especificidade dos letramentos acadêmicos e dos letramentos pedagógicos, têm importantes implicações para a formação do docente de língua materna. Desde Street, passando por outras pesquisas desenvolvidas dentro e fora do Brasil, especialmente as que aqui arrolamos, mostram a relevância de considerarmos os estudos críticos do letramento na especificidade da esfera acadêmica.

Notadamente nos cursos de formação de professores de língua, além da consideração dos letramentos acadêmicos em seu contexto ideológico e de poder, as práticas de letramento pedagógico são necessárias para a formação docente e para a constituição da identidade profissional. As práticas sociais que constituem a identidade do sujeito na universidade e sua identidade como docente são perpassadas por usos da escrita e cabe aos formadores na relação com o futuro docente promover práticas de letramento que oportunizem sua formação para usar a escrita e para ensiná-la. Tais conceitos vivenciados na formação inicial contribuem para 
que o docente tenha segurança e convicção para ensinar a escrita na Educação Básica numa perspectiva crítica e relevante para a formação do sujeito-cidadão.

Consideramos a relevância dessa discussão para formadores e professores em formação, de maneira que estejam aptos a assumir uma postura crítica frente às práticas de escrita durante os processos de formação inicial, no que diz respeito à (re)construção de conhecimentos das diversas áreas e, em especial, para o desenvolvimento de conhecimentos necessários ao ensino da escrita e à ampliação dos letramentos junto aos alunos da Educação Infantil ao Ensino Médio.

Diante disso, julgamos importante futuras pesquisas que se ocupem do estudo dos currículos dos cursos de Pedagogia e Letras no que diz respeito à abordagem aos estudos dos letramentos e o ensino da escrita na Educação Básica. Também entendemos que tais estudos são necessários à formação dos formadores desses cursos, independente de sua área de atuação, já que todos promovem e participam de práticas de letramentos acadêmicos que propiciam a constituição do profissional da educação. Esse seria um outro viés da pesquisa, de modo a investigar, analisar e problematizar junto aos professores formadores como as práticas sociais com a escrita em suas respectivas disciplinas têm promovido a aproximação com a escrita acadêmica e a ampliação das habilidades de escrita nos gêneros próprios a essa esfera; e também como tais práticas podem promover a constituição da identidade docente e a formação para o ensino da escrita.

\section{REFERÊNCIAS}

BALADELI, Ana Paula Domingos. Questões de identidade em sala de aula: que sentidos de brasilidade apresentam os livros didáticos. In FERreirA, A. de J. (Org.) As Políticas do Livro Didático e Identidades Sociais de Raça, Gênero, Sexualidade e Classe em Livros Didáticos. Campinas, SP: Pontes Editores, 2014. p. 225-242.

Botelho, Laura Silveira. Práticas de Letramentos Acadêmicos na escrita da monografia: relações de poder na Academia. 2016. 274f. Tese (Doutorado em Linguística) Universidade Federal de Juiz de Fora, Juiz de Fora, 2016.

CAVALCANTI, Marilda C. Educação linguística na formação de professores de línguas: intercompreensão e práticas translíngues. In: MOITA LOPES, L. P. (Org.) Linguística Aplicada na modernidade recente. São Paulo: Parábola Editorial, 2013. p. 211-226.

COLAÇO, Silvania Faccin. A travessia do ser aluno para o ser professor: práticas de letramento pedagógico no PIBID. 2015, $212 f$. Tese (Doutorado em Letras) Universidade Católica de Pelotas (UCPEL), Pelotas, 2015.

FIAD, Raquel Salek. A escrita na universidade. Revista da ABRALIN, v. Eletrônico, n. Especial, p. 357-369. $2^{\mathrm{a}}$ parte, 2011.

FROTA, Joyce Almagro Squinello. Letramentos Acadêmicos e o processo de representação dos graduandos em Letras na contemporaneidade. 2013, 150f. Dissertação (mestrado) Universidade Estadual Paulista "Júlio de Mesquita Filho", Instituto de Biociências, Letras e Ciências Exatas, São José do Rio Preto, 2013. 
GUEDES-PINTO, Ana Lúcia. Práticas de escrita no ensino universitário e suas relações com a formação docente. SCRIPTA, Belo Horizonte, v. 16, n. 30, p. 137-149, $1^{\circ}$ sem. 2012.

JUCHUM, Maristela. A escrita na universidade: uma reflexão com base no que os alunos dizem em seus textos. Horizontes de Linguística Aplicada, ano 13, n. 1, p. 107-129, 2014.

KLEIMAN, Angela B. Modelos de letramento e as práticas de alfabetização na escola. In: Os significados do letramento: uma nova perspectiva sobre a prática da escrita. Campinas, SP: Mercado dos Letras, 2001 [1995], p.15-64.

. Os estudos de letramento e a formação do professor de língua materna. Linguagem em (Dis)curso, v. 8, n. 3, p. 487-517, set./dez. 2008.

OLIVEIRA, Maria Bernadete Fernandes de. Revisitando a formação de professores de língua materna: teoria, prática e construção de identidades. Linguagem em (Dis)curso, v.6, n.I, p.101-117, 2006.

ROJO, Roxane. Letramentos múltiplos, escola e inclusão social. São Paulo: Parábola Editorial, 2009.

STREET, Brian. (Tradução de BAGNO, M.). Perspectivas interculturais sobre o letramento. Filologia e Linguística Portuguesa, n. 8, p. 465488, 2006 [1994].

Recebido para publicação em 21 ago. 2017. Aceito para publicação em 17 out. 2017 